\title{
Female fitness is increased by frequent mating in grasshoppers
}

\author{
M. C. PARDO, M. D. LÓPEZ-LEÓN, G. M. HEWITT† \& J. P. M. CAMACHO* \\ Departamento de Genética, Universidad de Granada, 18071 Granada, Spain and $†$ School of Biological Sciences, \\ University of East Anglia, Norwich NR4 7TJ, U.K.
}

\begin{abstract}
Radiolabelling experiments with Eyprepocnemis plorans demonstrated that males transfer proteinaceous substances with the ejaculate that are subsequently incorporated into the eggs that the females lay. The amount of male radioactive nutrients detected in the eggs was positively correlated to mating frequency, and the proportion incorporated was almost twice that of egg weight relative to female weight. This might suggest the existence of a specific mechanism selectively incorporating male ejaculate nutrients into the eggs. Another series of experiments with four types of female differing in mating frequency and male availability demonstrated that female production of eggs and embryos is directly proportional to mating frequency. This improvement in female fecundity is from the ejaculate nutrient transfer and both effects are directly dependent on mating frequency. Furthermore, in females crossed sequentially with two different males, there was a significant increase in mating frequency when the female was given the second male. This could be due to an increased mating effort of the second male to displace paternity of the previous male. The low paternity confidence and the polygynandric mating system that characterize $E$. plorans suggest that male ejaculate nutrients most likely function as a kind of mating effort rather than paternal investment.
\end{abstract}

Keywords: ejaculate nutrient transfer, fecundity, mating effort, multiple mating, parental investment, sperm competition.

\section{Introduction}

Paternal care is rare in insects, but males of many species still contribute to female and offspring fitness by providing nutrients with their ejaculate and thus may influence the pattern of sexual selection (Trivers, 1972; Thornhill, 1976). Some species, such as tettigoniids, have an external spermatophore which contains, in addition to sperm, a considerable quantity of nutrients that are eaten by the female after mating (Gwynne, 1990). Insects with an internal spermatophore, such as grasshoppers (Friedel \& Gillot, 1977), butterflies (Boggs \& Gilbert, 1979), cockroaches (Mullins \& Keil, 1980) and Drosophila (Markow \& Ankney, 1984), also provide nutrients with the ejaculate that are absorbed in the female genital tract and may be incorporated into eggs. This contribution might be a kind of male parental investment because it enhances egg production by recipient females (Boggs \& Gilbert, 1979; Gwynne, 1981; Steele, 1986; Butlin et al., 1987) and represents a cost for males (Gwynne, 1990 ), but only in species with high paternity confidence for males (Gwynne, 1984). For instance,

*Correspondence.
Markow et al., (1990) demonstrated in Drosophila mojavensis that a male's donations do not nutrify his own offspring because there is a lag in incorporation into the eggs so that his donations often invest in the next mating male's offspring. Thus most recent studies suggest that these male donations represent mating effort, rather than paternal investment, from the male's perspective (e.g. Simmons \& Gwynne, 1993; Simmons et al., 1993). Here we report evidence that males of the grasshopper Eyprepocnemis plorans provide females with proteinaceous nutrients that are transferred with the ejaculate and are actively incorporated into the eggs that she subsequently lays. Both the incorporation of male-derived nutrients into eggs and the rate of egg production by females are directly dependent on mating frequency, which demonstrates a direct cause-effect relationship for this type of male reproductive investment.

\section{Materials and methods}

\section{Radiolabel experiments}

Last instar nymphs of Eyprepocnemis plorans were collected at Salobreña in the province of Granada 
(Spain). All males used in these experiments were first placed with females (that then were discarded for these experiments) to discharge their sperm. When all the experimental males had copulated, they were injected with $30 \mu \mathrm{L}$ of a solution containing a mixture of 16 different amino acids radioactively marked with ${ }^{14} \mathrm{C}$ (radioactive concentration $=50 \mu \mathrm{Ci} / \mathrm{mL}$ ). Two days later each male was placed in a cage with a female. Simultaneously, control crosses were started with males that had not been injected with the solution. After each mating a sample of haemolymph was taken from the female. A total of three samples per cross was taken in the majority of crosses, but only two in crosses nos 8 and 12 . One or two egg-pods were obtained from each experimental cross to sample eggs for the presence of radioactive amino acids, and four egg-pods were analysed from control crosses. For this purpose, cages were provided with sterilized sand that was checked daily for the presence of egg-pods.

Haemolymph samples $(10 \mu \mathrm{L})$ were soaked in a piece of filter paper of $1 \mathrm{~cm}$ diameter, and stored in the dark in a scintillation vial. Eggs were dissected out of the pod, counted and weighed ( 80 of them). Three sets of five eggs each were squashed on a $1 \mathrm{~cm}$ diameter filter paper and stored in the dark in a scintillation vial.

For scintillation counting, $1 \mathrm{~mL}$ of tissue solubilizer was added to each sample. After $24 \mathrm{~h}$ at room temperature $10 \mathrm{~mL}$ of scintillation liquid was added; $24 \mathrm{~h}$ later all vials were counted in a Packard Tri-Carb 300 counter.

The proportional amount of radioactive amino acids transferred to eggs $\left(A_{\mathrm{e}}\right)$ was estimated from the quotient between total radioactive signal in the eggs and that of the female haemolymph before the eggs were laid. Total radioactivity in the eggs is calculated as follows: if five eggs that weigh $5 \times W_{\mathrm{e}}$ (mean weight per egg $=0.00491 \mathrm{~g}$ ) showed a certain radioactive count $\left(C_{\mathrm{e}}\right)$, then $N$ eggs in a certain pod (that weigh $N \times W_{\mathrm{e}}$ ) should show a radioactive signal equal to $C_{\mathrm{e}} \times \mathrm{N} / 5$.

Radioactive signal in the female before laying is equal to the sum of radioactivity remaining in the female body (measured in haemolymph) and that in the eggs she laid. Thus, $A_{\mathrm{e}}$ in a certain pod is equal to:

$A_{\mathrm{e}}=\frac{C_{\mathrm{e}} N 5}{\left(C_{\mathrm{f}} W_{\mathrm{f}} / 0.01\right)+\left(C_{\mathrm{e}} N / 5\right)}$,

where $C_{\mathrm{e}}=$ count in 5 eggs, $N=$ number of eggs in the pod, $C_{\mathrm{f}}=$ count in the female just before laying, and $W_{\mathrm{f}}=$ average weight of females $(1.47447 \mathrm{~g})$. Assessing $C_{\mathrm{f}}$ is a problem because pod-laying rarely coincided with female sampling. This was solved by extrapolating $C_{\mathrm{f}}$ from the temporal change of female counts over the three samples taken.
Experiments to analyse the relationship between the rate of copulation and the rate of egg and embryo production

Males and females were collected in the field as last instar nymphs in order to guarantee their virginity. The following four types of female were analysed with respect to male availability and the rate of copulation. Type 1: females that performed only one copulation, after that the male was removed from the cage. The remaining females always had at least one male during the whole experiment, and the copulation rate was recorded. Type 2: females that were placed with one male until they laid about two egg-pods. Type 3: the male in type 2 crosses was substituted by another male, and the period that these same females remained with the second male has been designated as type 3 . The practical difference between type 2 and type 3 females is that in the latter sperm competition is taking place, as there is paternity displacement in this species. Type 4: females that were placed in a cage with two males, one of which was marked on the pronotum with nail varnish in order to distinguish and record the copulations of each male.

Thus, type 1 females are strictly single-mated females, type 2 are multiply mated females with the same male, type 3 are the same individuals as type 2 females but in a situation of sperm competition, and type 4 are multiply mated females with double the male availability of type 2 and type 3 females. The experiments with type 1 females lasted for all their lives. Thus, a possible decay in their productivity at the end of their lives could bias our results because the other types of female were still productive throughout the experiment. In fact, some of the type 1 females spent their two final months without laying a pod, which suggests depletion of the sperm from their single copulation (López-León et al., 1994). For this reason, the duration of all the experiments, including those with type 1 females has been taken to the last egg-pod. Similarly, the time between the initiation of the experiment and the first mating may depend on a number of factors, such as age. Consequently, the experiments were considered to start when the first mating occurred. Thus, the rate of copulation is defined as the number of copulations performed between the first mating and the last egg-pod.

Egg-pods were dissected and the numbers of eggs and embryos per pod were counted. Crosses were examined daily in order to record the rate of copulation and the rate of laying. Since copulation duration is frequently longer than 24 h (López-León et al.,, 1994), two daily observations were sufficient. 


\section{Results and discussion}

\section{Nutrient transfer to eggs}

The results of 12 experimental crosses with Eyprepocnemis plorans showed that radiolabelled males transferred significant amounts of radioactive amino acids to females, and that these were subsequently incorporated into the eggs that females laid (Table 1). Spearman rank correlation analyses (Table 2) showed that the radioactive counts in female haemolymph were not significantly correlated with the number of days from male injection, the number of matings that occurred before the sample was taken, nor the number of days from first mating. This may be because the female haemolymph is a transient medium for nutrients in their passage from male spermatophore to the eggs. However, as each copulation in E. plorans is very long and frequently lasts $>1$ day, the total time spent copulating may be a more appropriate measure of mating frequency in this species than simply the number of copulations, and such an analysis indeed demonstrated a significant positive correlation between the radioactive counts in female haemolymph and the number of days that she had been seen copulating, at least in the two first samples (Table 2).

In the eggs counts were positively correlated with the number of copulations (in both the first and the second pods), the number of days from the first mating (in the second pod) and the number of days seen copulating (in both pods; Table 2). The highest correlation coefficients were shown by the number of copulations. Thus, ejaculate nutrient transfer to the eggs was significantly dependent on copulation rate.

Table 3 shows a calculation of the amount of radioactive counts in the eggs $\left(A_{\mathrm{e}}\right)$ relative to the counts in female haemolymph $\left(C_{\mathrm{f}}\right) . A_{\mathrm{e}}$ is shown to be higher than the weight of egg-pods relative to female weight in 15 of the 19 egg-pods analysed (Wilcoxon signed rank test: $P=0.0048)$. The median $A_{\mathrm{e}}$ value (27.51 per cent) was almost double the median relative weight of eggs (16.64 per cent). This suggests that ejaculate

Table 1 Ejaculate nutrient transfer in Eyprepocnemis plorans

\begin{tabular}{|c|c|c|c|c|c|c|c|}
\hline \multirow[b]{2}{*}{ Type of sample } & \multirow[b]{2}{*}{ Type of cross } & \multicolumn{2}{|c|}{ Radioactive counts } & \multirow{2}{*}{$\begin{array}{l}\text { Number } \\
\text { of } \\
\text { crosses }\end{array}$} & \multicolumn{3}{|c|}{ Student's $t$-test } \\
\hline & & Mean & SE & & $t$ & d.f. & $P$ \\
\hline Female haemolymph & $\begin{array}{l}\text { Experimental } \\
\text { Control }\end{array}$ & $\begin{array}{r}43.83 \\
4.70\end{array}$ & $\begin{array}{l}4.05 \\
0.70\end{array}$ & $\begin{array}{c}12 \\
5\end{array}$ & 12.39 & 15 & $<0.0001$ \\
\hline Eggs & $\begin{array}{l}\text { Experimental } \\
\text { Control }\end{array}$ & $\begin{array}{r}362.12 \\
8.25\end{array}$ & $\begin{array}{r}65.62 \\
1.70\end{array}$ & $\begin{array}{c}11^{+} \\
5\end{array}$ & 13.89 & 14 & $<0.0001$ \\
\hline
\end{tabular}

¥The female in cross no. 8 did not lay eggs before dying.

The data were transformed into natural logarithms to equalize variances and apply Student's $t$-test.

Table 2 Spearman rank correlation $\left(r_{\mathrm{s}}\right)$ analyses between radioactive counts and four variables measured during the course of experimental crosses of Eyprepocnemis plorans

\begin{tabular}{|c|c|c|c|c|c|c|c|c|c|c|}
\hline \multirow{2}{*}{$\begin{array}{l}\text { Type of } \\
\text { individual }\end{array}$} & \multirow[b]{2}{*}{ Variable } & \multicolumn{3}{|c|}{ First sample } & \multicolumn{3}{|c|}{ Second sample } & \multicolumn{3}{|c|}{ Third sample } \\
\hline & & $r_{\mathrm{s}}$ & d.f. & $P$ & $r_{\mathrm{s}}$ & d.f. & $P$ & $r_{\mathrm{s}}$ & d.f. & $P$ \\
\hline \multirow[t]{4}{*}{ Females } & Days from male injection & -0.26 & 11 & 0.39 & 0.18 & 11 & 0.56 & -0.40 & 9 & 0.22 \\
\hline & Number of matings & -0.32 & 11 & 0.29 & -0.01 & 11 & 0.98 & -0.16 & 9 & 0.65 \\
\hline & Days from first mating & -0.15 & 11 & 0.15 & 0.22 & 11 & 0.47 & -0.24 & 9 & 0.48 \\
\hline & Number of days mating & 0.59 & 11 & 0.03 & 0.61 & 11 & 0.03 & 0.31 & 9 & 0.36 \\
\hline \multirow[t]{4}{*}{ Eggs } & Days from male injection & 0.23 & 10 & 0.48 & 0.41 & 7 & 0.27 & - & - & - \\
\hline & Number of matings & 0.81 & 10 & $<0.01$ & 0.79 & 7 & 0.01 & - & - & - \\
\hline & Days from first mating & 0.43 & 10 & 0.16 & 0.69 & 7 & 0.04 & - & - & - \\
\hline & Number of days mating & 0.70 & 10 & 0.01 & 0.69 & 7 & 0.04 & - & - & - \\
\hline
\end{tabular}

First and second egg samples correspond to the first and second pods.

Significant correlation coefficients are given in bold-type. 
Table 3 Calculation of the relative amount of radioactive amino acids transferred to eggs $\left(A_{\mathrm{e}}\right)$ and the relative weight of eggs $\left(R W_{\mathrm{e}}\right)$ in the 19 egg-pods analysed of Eyprepocnemis plorans

\begin{tabular}{ccrrrrr}
\hline Cross & Pod & \multicolumn{1}{c}{$C_{\mathrm{f}}$} & \multicolumn{1}{c}{$N$} & \multicolumn{1}{c}{$C_{\mathrm{e}}$} & $A_{\mathrm{e}}(\%)$ & $R W_{\mathrm{e}}(\%)$ \\
\hline 1 & 1 & 56.70 & 74 & 13.11 & 2.268 & 24.628 \\
& 2 & 35.48 & 72 & 395.06 & 52.094 & 23.962 \\
2 & 1 & 39.00 & 44 & 878.41 & 57.342 & 14.644 \\
& 2 & 82.11 & 56 & 793.09 & 42.319 & 18.637 \\
3 & 1 & 113.80 & 36 & 724.25 & 23.709 & 11.981 \\
& 2 & 179.86 & 26 & 720.20 & 12.374 & 8.653 \\
4 & 1 & 72.36 & 65 & 330.18 & 28.689 & 21.633 \\
& 2 & 69.28 & 59 & 466.22 & 35.004 & 19.636 \\
5 & 1 & 42.55 & 43 & 99.29 & 11.980 & 14.311 \\
& 2 & 63.24 & 37 & 399.78 & 24.085 & 12.314 \\
6 & 1 & 52.77 & 29 & 233.06 & 14.801 & 9.652 \\
& 2 & 36.60 & 50 & 371.53 & 40.774 & 16.641 \\
7 & 1 & 17.07 & 44 & 229.60 & 44.529 & 14.644 \\
& 2 & 3.02 & 61 & 440.68 & 92.342 & 20.301 \\
9 & 1 & 67.78 & 46 & 144.56 & 11.745 & 15.309 \\
10 & 1 & 45.78 & 62 & 81.52 & 13.025 & 20.634 \\
& 2 & 90.46 & 57 & 443.99 & 27.509 & 18.970 \\
11 & 1 & 86.19 & 20 & 270.98 & 7.859 & 6.656 \\
12 & 1 & 42.86 & 71 & 257.85 & 36.684 & 23.630 \\
\hline
\end{tabular}

$C_{\mathrm{f}}:$ radioactive counts in the female just before laying; $N$ : number of eggs in the pod; $C_{\mathrm{e}}$ : radioactive counts in the egg sample. nutrients are not randomly incorporated into eggs, but that some preferential mechanism exists in E. plorans females for this process. This contrasts with our observation by similar techniques that in the locust $L$. migratoria proteinaceous ejaculate nutrients are simply incorporated proportionately into the eggs (Pardo et al., 1994).

\section{Mating strategies}

The second part of our investigation sought to ascertain whether ejaculate nutrient transfer has any effect on male and female fitnesses by enhancing the production of offspring. For this purpose, egg and embryo productivities were analysed for four types of female differing in male availability and copulation frequency. From the results shown in Table 4, it is apparent that all types of multiply mated females (types 2,3 and 4 ) copulated several times before their first egg-pod but only once between consecutive pods, and there were no significant differences among types for both these variables (nos 6 and 7 in Table 4). Interestingly, although type 3 females are the same individuals as type 2 ones, they behaved in type 3 crosses as though they had not had previous sexual experience. Thus, when these females were given the first male (type 2 ) they mated several times (median $=4$ ) until the first egg-pod was laid. Afterwards, however, they mated

Table 4 Comparison of eight fitness-related variables among four types of experimental Eyprepocnemis plorans females

\begin{tabular}{|c|c|c|c|c|c|c|c|}
\hline \multirow[b]{2}{*}{ Variable } & \multicolumn{4}{|c|}{ Type of female } & \multicolumn{3}{|c|}{ Kruskal-Wallis test } \\
\hline & $\begin{array}{l}\text { Type } 1 \\
(N=10)\end{array}$ & $\begin{array}{l}\text { Type } 2 \\
(N=11)\end{array}$ & $\begin{array}{l}\text { Type } 3 \\
(N=11)\end{array}$ & $\begin{array}{l}\text { Type } 4 \\
(N=8)\end{array}$ & $H$ & d.f. & $P$ \\
\hline Days between the first and the last egg-pods & 94.50 & 37.00 & 22.00 & 28.50 & - & - & - \\
\hline 1. Number of eggs per day & 2.20 & 2.11 & 2.82 & 5.43 & 14.31 & 3 & 0.0025 \\
\hline 2. Number of embryos per day & 1.84 & 2.04 & 2.50 & 4.97 & 14.41 & 3 & $\mathbf{0 . 0 0 2 4}$ \\
\hline 3. Days between consecutive egg-pods & 19.85 & 15.67 & 11.33 & 8.50 & 23.25 & 3 & $<0.0001$ \\
\hline $\begin{array}{l}\text { 4. Female remating interval before the first pod } \\
\text { (in days) }\end{array}$ & - & 6.75 & 5.00 & 5.50 & 3.90 & 2 & 0.2721 \\
\hline $\begin{array}{l}\text { 5. Female remating interval after the first pod } \\
\text { (in days) }\end{array}$ & - & 10.60 & 14.00 & 7.20 & 6.01 & 2 & 0.0496 \\
\hline 6. Number of copulations before the first pod & 1 & 4.00 & 2.00 & 3.50 & 3.35 & 2 & 0.1869 \\
\hline $\begin{array}{l}\text { 7. Number of copulations between consecutive } \\
\text { egg-pods }\end{array}$ & - & 1.00 & 1.00 & 1.29 & 0.25 & 2 & 0.8846 \\
\hline 8. Number of copulations per day & 0.01 & 0.09 & 0.15 & 0.17 & 24.16 & 3 & $<0.0001$ \\
\hline
\end{tabular}

$N=$ number of females.

Median values are expressed for all variables. In variables showing significant differences between female types, $P$ values are given in bold-type. 
only once between consecutive egg-pods. When these same females were then given the second male (type 3 ), again they mated several times (median $=2$ ) until the following egg-pod was laid (this was in fact the first eggpod sired by the second male). Afterwards, they mated once with the second male between consecutive pods. A Wilcoxon signed rank test showed that these two variables (nos 6 and 7 in Table 4) were significantly different in type 3 crosses $(P=0.0113)$ and type $2+$ type 3 crosses $(P=0.0001)$. The increase in the number of copulations with the second male is most likely a consequence of second male strategies to achieve paternity displacement, which is the norm in $E$. plorans (López-León et al., 1993). Increases in male mating effort in situations with risk of sperm competition have also been reported in rats (Bellis et al., 1990), the beetle Tenebrio molitor (Gage \& Baker, 1991) and the Mediterranean fruit fly, Ceratitis capitata (Gage, 1991). Such observations agree with predictions of sperm competition theory (Parker, 1990a,b).

\section{Effects on fitness}

The comparison of eight fitness-related variables (nos 1 to 8 in Table 4) among the four types of female showed significant differences for five of them: (i) the number of eggs per day, (ii) the number of embryos per day, (iii) the number of days between consecutive eggpods, (iv) the female remating interval after the first egg-pod, and ( $v$ ) the number of copulations per day. The first two are measures of female productivity of offspring and increased from type 1 to type 4 females. As Fig. 1 shows, offspring productivity was directly

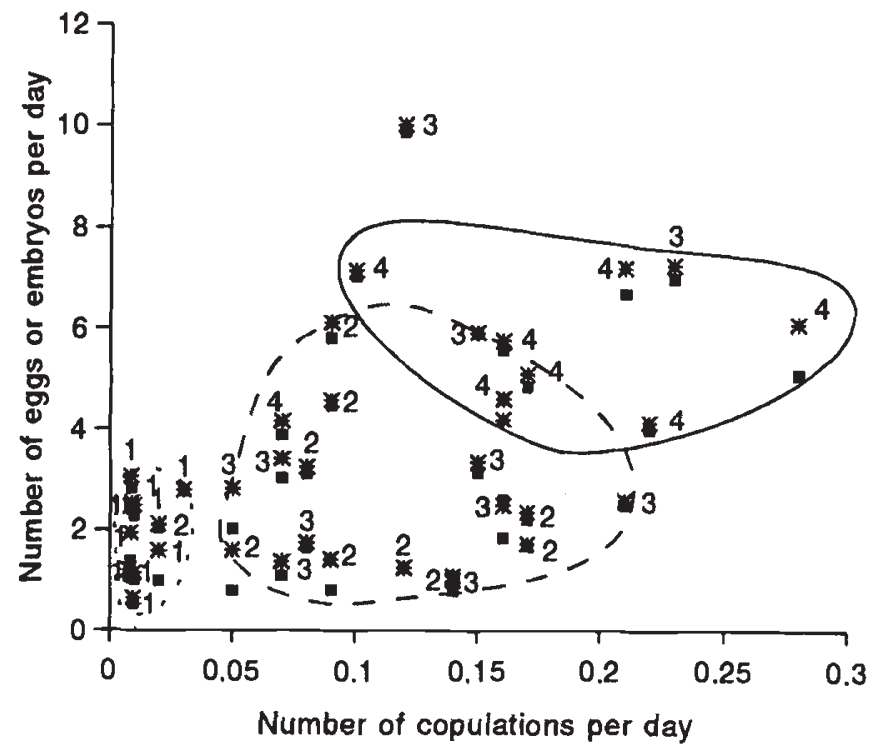

dependent on copulation rate. This was achieved through a shortening in the number of days between consecutive egg-pods with increasing copulation rate (see Table 4).

The three remaining variables are related to egg-pod laying and copulation. Our results indicate that eggpod laying rate increased significantly from type 1 to type 4 females. Interestingly, type 2-3 females showed significantly higher egg-pod laying rate when paired with the second male than they did with the first male (Wilcoxon signed rank test: $T=7, P=0.02, N=11$ ). This indicates that the higher mating effort of the second male, presumably performed for sperm competition, may accelerate egg-pod laying rate and hence improve female fitness. The third item suggests that the time for female remating after the first egg-pod is laid depends mainly on male availability and, perhaps, on sperm competition risks too. Thus, as Table 4 shows, type 4 females, that possessed double male availability and both males were engaged in sperm competition during the whole experiment, remated much faster after the first egg pod than type 2-3 females that had single male availability and paternity displacement had already been achieved (in type 3 females).

\section{General Discussion}

Male contribution in the form of proteinaceous nutrients in the ejaculate is frequent in insects with internal spermatophores, such as grasshoppers (Friedel \& Gillot, 1977; Butlin et al., 1987; Pardo et al., 1994), butterflies (Boggs \& Gilbert, 1979), cockroaches (Mullins et al., 1992) and Drosophila (Pitnick et al., 1991). It has been demonstrated separately that ejacu-

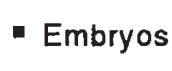

* Eggs
Fig. 1 Relationship between mating frequency and offspring production rate in four types of female (1 to 4 ) of the grasshopper Eyprepocnemis plorans. The area within the dotted line includes all type 1 (single mated) females, that enclosed by a discontinuous line includes the majority of type 2-3 (multiply mated, single male availability) females, and that within the continuous line contains the majority of type 4 (multiply mated, double male availability) females. 
late nutrient transfer (Mullins et al., 1992) and its beneficial effects on female fitness (Butlin et al., 1987) are both dependent on diet, being particularly evident in low protein diet situations. We have demonstrated here that the rates of ejaculate nutrient transfer and of egg and embryo production in E. plorans increase in parallel with mating frequency, even though we fed our grasshoppers ad libitum. This indicates that copulation feeding is a very important male contribution to the improvement of female fitness in this species, and predicts that some kind of female choice for males producing larger spermatophore investment could be operating in the field.

The present investigation confirms the hypothesis that species in which males provide benefits to their mates show high levels of last male sperm precedence (Walker, 1980; Gwynne 1984); E. plorans is characterized by highly significant male reproductive investment, in the form of proteinaceous nutrients present in the ejaculate and transferred to females and eggs thereby improving female fitness (this paper), and there is last male sperm precedence (López-León et al., 1993). Futhermore, there is a second male strategy to assure paternity, namely a very prolonged copulation ( 1 or 2 days). However, these two mechanisms do not seem enough to guarantee a high paternity confidence for $E$. plorans males; this is suggested by the fact that males that had to displace the sperm of the first male crossed with type 3 females, actually increased their mating frequency. Since multiple mating operates in $E$. plorans natural populations (M. D. López-León et al., unpublished data), the mating system of this species is most likely polygynandry, because males are unlikely to be able to remate the same female in the field. It could well be the same in most grasshopper species. The low paternity confidence makes it highly uncertain that a male's ejaculate nutrients are invested in his own offspring. Hence, from the male point of view, ejaculate nourishment is most likely a kind of mating effort rather than paternal investment.

In conclusion, the main strategies to assure paternity in E. plorans seem to be: (i) to copulate very frequently, and (ii) to perform a very prolonged copulation, as a way for mate guarding. Both strategies are beneficial for females because they receive nutrients that increase their reproductive output. Frequent mating is also beneficial for males because it increases male paternity probability by increasing the chance of being the last male mated to a female immediately before laying. These reproductive activities, however, are costly for both sexes; males have the costs of producing nutrients to incorporate into the ejaculate and of a prolonged copulation for mate guarding thus losing opportunities of inseminating other females. But the most important cost for both members of couples is predation risk, because they cannot fly and have much more difficulty in jumping. Predation risk, however, may be highly variable among populations depending on predator density. This could even mean that copulation duration may be variable among populations as a result of a survival-reproduction trade-off.

\section{Acknowledgements}

We thank P. Croghan for his help with radiolabel experiments. This study was supported by grants from the NERC and SERC (UK), and the Spanish DGICYT (PB93-1108) and Plan Andaluz de Investigación (Grupo no. 3122).

\section{References}

BELLIS, M. A., BAKER, R. R. AND GAGE, M. J. G. 1990. Variation in rat ejaculates is consistent with the kamikaze sperm hypothesis. J. Mammal., 71, 479-480.

BOGGS, C. L. AND GILBERT, L. E. 1979. Male contribution to egg production in butterflies: evidence for transfer of nutrients at mating. Science, 206, 83-84.

BUTLIN, R. K., WOODHATCH, C. W. AND HEWITT, G. M. 1987. Male spermatophore investment increases female fecundity in a grasshopper. Evolution, 41, 221-225.

FRIEDEL, T. AND GILlOTT, c. 1977. Contribution of maleproduced proteins to vitellogenesis in Melanoplus sanguinipes. J. Insect Physiol., 23, 145-151.

GAGE, M. J. G. 1991. Risk of sperm competition directly affects ejaculate size in the Mediterranean fruit fly. Anim. Behav., 42, 1036-1037.

GAGE, M. J. G. AND BAKER, R. R. 1991. Ejaculate size varies with socio-sexual situation in an insect. Ecol. Entomol., 16, 331-337.

GWYNNE, D. T. 1981. Sexual difference theory: Mormon crickets show role reversal in mate choice. Science, 213, 779-780.

GWYNNE, D. T. 1984. Male mating effort, confidence of paternity and insect sperm competition. In: Smith, R. L. (ed.) Sperm Competition and the Evolution of Animal Mating Systems, pp. 117-149. Academic Press, New York.

GWYNNE, D. T. 1990. Testing parental investment and the control of sexual selection in katydids: the operational sex ratio. Am. Nat., 136, 474-484.

LOPEZ-LEON, M. D., CABRERO, J., PARDO, M. C., VISERAS, E. AND CAMACHO, J. P. M. 1993. Paternity displacement in the grasshopper Eyprepocnemis plorans. Heredity, 71, 539-545.

LOPEZ-LEON, M. D., PARDO, M. C., CABRERO, J. AND CAMACHO, J. P. M. 1994. Dynamics of sperm storage in the grasshopper Eyprepocnemis plorans. Physiol. Entomol., 19, 46-50.

MARKOW, T. A. AND ANKNEY, P. F. 1984. Drosophila males contribute to oogenesis in a multiple mating species. Science, 224, 302-303.

MARKOW, T. A., GALLAGHER, P. D. AND KREBS, R. A. 1990. Ejaculate-derived nutritional contribution and female reproduc- 
tive success in Drosophila mojavensis (Patterson and Crow). Funct. Ecol., 4, 67-73.

MULLINS, D. E. AND KEIL, C. B. 1980. Paternal investment of urates in cockroaches. Nature, 283, 567-569.

MULLINS, D. E., KEIL, C. B. AND WHITE, R. H. 1992. Maternal and paternal nitrogen investment in Blattella germanica (L.) (Dictyoptera; Blattellidae). J. Exp. Biol., 162, 55-72.

PARDo, M. C., CAMACHO, J. P. M. AND HewitT, G. M. 1994. Dynamics of ejaculate nutrient tranfer in Locusta migratoria. Heredity, 73, 190-197.

PARKER, G. A. 1990a. Sperm competition games: raffles and roles. Proc. R. Soc. B., 242, 120-126.

PARKER, G. A. 1990b. Sperm competition games: sneaks and extra-pair copulations. Proc. R. Soc. B., 242, 127-133.

PITNICK, S., MARKOW, T. A. AND RIEDY, M. F. 1991. Transfer of ejaculate and incorporation of male-derived substances by females in the nannoptera species group (Diptera: Drosophilidae). Evolution, 45, 774-780.
SIMMONS, L. W., CRAIG, M., LLORENS, T., SCHINZIG, M. AND HOSKEN, D. 1993. Bush-cricket spermatophores vary in accord with sperm competition and parental investment theory. Proc. R. Soc. B., 251, 183-186.

SIMMONS, L. W. AND GWYNNE, D. T. 1993. Reproductive investment in bush-crickets. The allocation of male and female nutrients to offspring. Proc. R. Soc. B., 252, 1-5.

STEELE, R. H. 1986. Courtship feeding in Drosophila subobscura $\mathrm{I}$. The nutritional significance of courtship feeding. Anim. Behav., 34, 1087-1098.

THORNHILL, R. 1976. Sexual selection and paternal investment in insects. Am. Nat., 110, 153-163.

TRIVERS, R. L. 1972. Parental investment and sexual selection. In: Campbell, B. (ed) Sexual Selection and the Descent of Man 1871-1971, pp. 136-179. Aldine, Chicago.

WALKER, W. F. 1980. Sperm utilization strategies in nonsocial insects. Am. Nat., 115, 780-799. 